\title{
Communication With Older Adults in Times of a Pandemic: Practical Suggestions for the Health Care Professionals
}

\author{
Alexis Pinsonnault-Skvarenina ${ }^{1,2 \star}$, Adriana Bender Moreira de Lacerda ${ }^{1,3}$, Mathieu Hotton ${ }^{4,5}$ \\ and Jean-Pierre Gagné $1,2,3,6$
}

${ }^{1}$ School of Speech-Language Pathology and Audiology, Faculty of Medicine, University of Montreal, Montreal, QC, Canada, ${ }^{2}$ Center for Interdisciplinary Research in Rehabilitation of Greater Montreal (CRIR), Montreal, QC, Canada, ${ }^{3}$ Research Center of the Institut universitaire de gériatrie de Montréal (CRIUGM), Montréal, QC, Canada, ${ }^{4}$ School of Rehabilitation, Faculty of Medecine, Université Laval, Québec, QC, Canada, ${ }^{5}$ Center for Interdisciplinary Research in Rehabilitation and Social Integration (CIRRIS), Québec, QC, Canada, ${ }^{6}$ Titulaire de la Chaire de la Fondation Caroline-Durand en audition et vieillissement de l'Université de Montréal, Montréal, Québec, QC, Canada

\section{OPEN ACCESS}

Edited by: Lucas Raquel,

University Porto, Portugal

Reviewed by: Rebecca Bennett, Ear Science Institute Australia, Australia Ana Cruz,

University of Porto, Portugal

*Correspondence: Alexis Pinsonnault-Skvarenina alexis.pinsonnault-skvarenina@ umontreal.ca

Received: 19 February 2021 Accepted: 01 April 2021 Published: 27 May 2021

Citation:

Pinsonnault-Skvarenina A, Lacerda ABM, Hotton M and Gagné J-P (2021) Communication With Older Adults in Times of a Pandemic: Practical Suggestions for the Health Care Professionals. Public Health Rev 42:1604046. doi: 10.3389/phrs.2021.1604046
In order to limit the spread of the coronavirus, several protective measures have been put in place in the community, in private and public residences and in health care centers. Some measures have a negative impact on communication. They include physical distancing, the use of face masks and shields as well as the increased use of telephone and videoconferencing for distance communication. The effects of COVID-19 are particularly harsh on older adults. Consequently, older adults, especially those with hearing loss, are particularly at risk of experiencing communication breakdowns and increased social isolation. Health care professionals should learn about and be encouraged to use communication strategies to maintain good interactions with their patients. This article proposes practical suggestions to health professionals who interact with older adults, especially those who have difficulty understanding speech. The goal of this article is to inform on the prevalence of hearing loss, the hearing difficulties experienced by older adults, the manifestations of hearing problems, the effects of pandemic protection measures on communication and the strategies that can be used to optimize professionalpatient communication during a pandemic.

Keywords: COVID-19, communication, hearing loss, face mask, health care

\section{BACKGROUND}

Coronaviruses are known to cause respiratory damage. A new strain of coronavirus, SARS-CoV-2 (Severe Acute Respiratory Syndrome Coronavirus 2), was identified in December 2019. The term COVID-19 refers to the infection caused by the virus, Coronavirus Disease 2019. Current scientific data shows that the virus is transmitted mainly by droplets of respiratory secretions (e.g., coughing, sneezing, and speaking). In order to limit the spread of the virus, several protective measures have been put in place in the community, private and public residences, as well as in health care centers. In addition to hand washing, social isolation and telecommuting, physical distancing and the use of a face mask, face shield and transparent partitions are recommended by public health agencies around the world [1]. 
Older individuals with hearing loss, whether they use hearing aids or not, learn to employ a variety of strategies to optimize speech understanding and communication [2-4]. For example, one strategy involves integrating visual speech cues (speechreading) and the auditory speech cues produced by the talker. In degraded communication settings, using visual speech cues may improve speech intelligibility by as much as $40 \%$ [5] or have the same effect as improving the signal-to-noise ratio (SNR) by $8-11 \mathrm{~dB}[6,7]$. Some measures proposed to counter the spread of COVID-19 have a negative impact on communication regardless of whether or not the individuals involved have hearing loss. For example, some of the proposed measures may result in hiding the lips and part of the face of the talker or they may interfere with the propagation of the acoustic signal generated by the talker. The negative impact on speech communication may be considerable and thus may have a deleterious effect on activities of daily living and on social and professional integration of people with hearing loss, especially older adults. Also, it may have a negative impact on the health care services they receive and on their adherence to the treatment regimen that is recommended for them. The COVID-19 pandemic brought about changes in the habits and social activities of almost everyone, including older individuals. For example, in-person social contacts have decreased and the use of distance communication involving technology (e.g., email, telephone, videoconferencing app) has increased appreciably.

In times of pandemic, special consideration should be given to communication among the population of older individuals with hearing loss. Communication with COVID-19 protection measures is problematic. Health care professionals should be aware of this and use strategies designed to optimize professionalpatient communication. Effective communication is a shared responsibility; it is not problematic only for persons with hearing loss.

This article is intended for all health care professionals who interact and provide services to older adults that experience difficulties understanding speech. The goal of this article is to provide practical strategies that can be used to optimize communication during the pandemic. The prevalence of hearing loss, the communication difficulties, the other manifestations of hearing problems and the effects of pandemic protection measures on communication are addressed. Although the information provided in the article is relevant for all adults with hearing loss, we will concentrate specifically on older adults.

\section{HEARING AND COMMUNICATION DIFFICULTIES OF OLDER ADULTS WITH HEARING LOSS}

According to the World Health Organization [8], there are 466 million persons in the world with disabling hearing loss $(6.1 \%$ of the world's population). Due to the increased longevity of individuals in most countries, the number of people with disabling hearing problems will continue to increase in the future. Projections show that the number could rise to 630

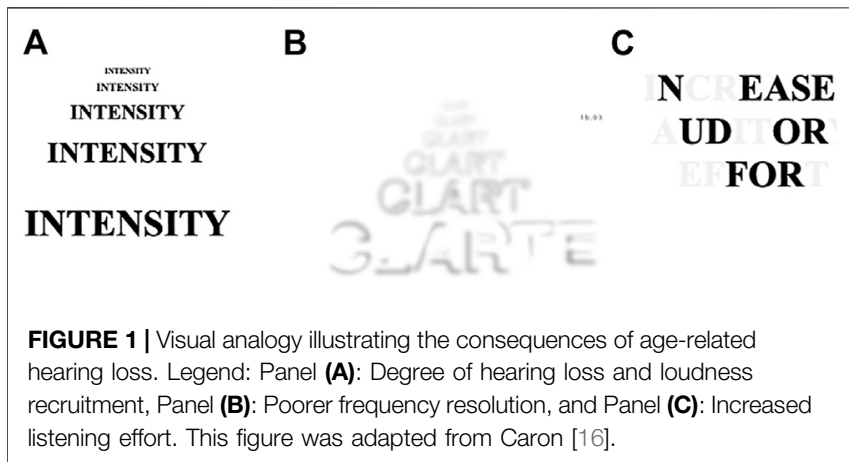

million by 2030 and may be over 900 million in 2050 [8]. The proportion of older adults with a hearing disability increases with age; while about $33 \%$ of adults over 65 years of age present with hearing loss [9], this proportion is more than twice as much among adults over 80 years of age-roughly $80 \%$ [10]. For older adults in nursing homes, it is estimated that the proportion of residents with hearing loss is over $80 \%$ [11].

Presbycusis, or age-related hearing loss (ARHL), is defined as an age-related elevation of hearing thresholds [12]. This hearing loss is associated with many changes in the auditory system, including at the level of the sensory cells of the inner ear, the stria vascularis, the auditory nerve and the spiral ganglion [13]. It is believed that ARHL does not have a single cause but originates from an interaction of several factors. These factors may be intrinsic (e.g., gender, genetic diseases and disorders, systemic diseases, high blood pressure and metabolic diseases) or extrinsic (e.g., noise exposure, ototoxic medication, smoking and diet) to the aging individual [13-15]. Clinically, ARHL manifests itself by a progressive decrease in hearing detection thresholds that initially affects the higher audiometric frequencies, and then progressively spreads to the lower frequencies. A visual analogy of ARHL is illustrated in Figure 1. One consequence of ARHL is a decrease in the intensity of soft auditory signals coded by the auditory nerve (see Figure 1, panel A). Another consequence is a reduction in the clarity of the auditory message (see Figure 1, panel B). As a result of a loss in hearing sensitivity as well as spectral, temporal and other types of auditory distortions, speech understanding becomes less "automatic" and additional cognitive resources are required to decode and interpret the spoken message (see Figure 1, panel C). There is undeniable evidence that the use of hearing aids significantly improves speech understanding and reduces the psychosocial consequences of ARHL [17]. Thus, it is highly recommended that individuals who have hearing loss use hearing aids. Notwithstanding this recommendation, the focus of the present article is to describe other strategies to optimize speech understanding when protective measures are used in a pandemic.

Many older adults report negative psychosocial and emotional consequences attributable to their hearing loss. For example, they may experience frustration and a reduced self-esteem due to the difficulties associated with understanding speech $[18,19]$. Because of the negative stereotypes and communication difficulties 


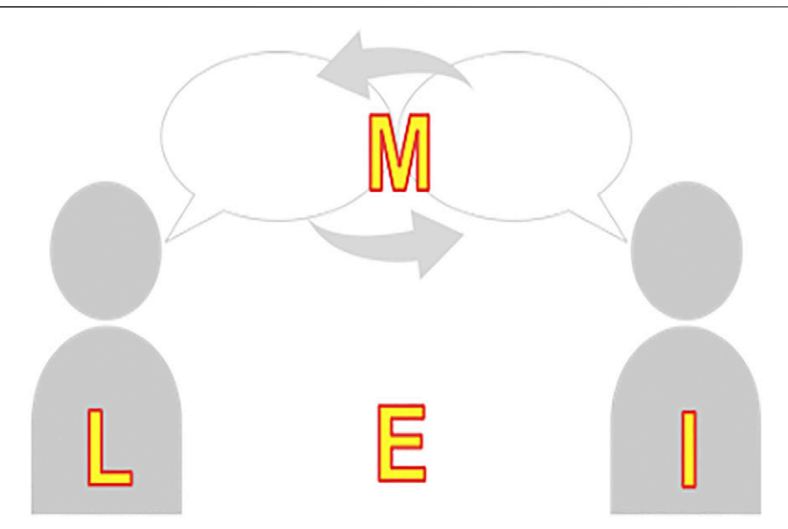

FIGURE 2 | The LIME speech communication model. Legend: This figure was adapted from Lacerda et al. [31]

associated with ARHL, some older adults avoid social gathering, including family reunions. This type of social isolation may result in loneliness, depression and other forms of physical and mental health conditions [20]. Also, fatigue caused by hearing difficulties can have secondary consequences such as increased stress and tension among couples and other family members [21]. There is an increasing amount of literature indicating an association between hearing loss and cognitive decline [22-24]. Specifically, the prevalence of hearing loss is higher among people with dementia than among older adults who do not have cognitive problems. There is ample evidence to confirm that the presence of hearing loss may have negative effects on the quality of life and health of spouses and other family members who may not have hearing problems, [25-28]. In short, the presence of hearing impairment can have a negative impact on several health conditions as well as one's quality of life.

\section{THE SPEECH COMMUNICATION CHAIN AND SOURCES OF COMMUNICATION BREAKDOWN}

The LIME model is a simplified illustration of the speech communication chain [29]. In line with the International Classification of Functioning, Disability and Health [30], this model can be used to identify potential sources of communication breakdowns during conversations between two or more individuals (see Figure 2). The LIME model outlines factors associated with the four main elements involved in speech communication: 1) the Listener, 2) the Interlocutor, 3) the Message and 4) the Environment. All four elements are equally important in the communication process. Likewise, factors associated with any one of these four elements may create an obstacle to communication and cause a communication breakdown. A communication breakdown is defined as a failure to exchange information, resulting in a lack of communication [29]. Whereas the four elements of the simplified speech communication chain can constitute obstacles to communication, manipulating one or more of the elements can serve to overcome or avoid a communication breakdown and facilitate a verbal exchange between two or more individuals.

A communication breakdown occurs when the listener (L), a person with hearing loss, does not understand the intended spoken information transmitted by the interlocutor (I). To understand speech, the listener must detect and recognize the relevant speech elements, use working memory to store the information and apply other cognitive functions to decode the information and generate an appropriate response [32]. The listener's psychological state (e.g., anxiety and stress level) may contribute to a communication breakdown. It is reported that older adults' performance on memory tasks are sensitive to their level of stress [33]. The cognitive resources required to address the increased level of anxiety and stress may cause speech understanding difficulties. A communication breakdown may also occur because the interlocutor's (I) speech is too soft, accentuated or distorted.

The message itself (M) can constitute the source of a communication breakdown. For example, a communication breakdown would occur if the listener is not knowledgeable of the vocabulary (e.g., medical terminology), language structure or cognitive concept being expressed by the interlocutor. Simplifying the language is a helpful strategy to use when communicating with an older person who has difficulty understanding the intended message.

Finally, and very importantly with regards to communication, the environment $(\mathrm{E})$ in which a conversation takes place may constitute a facilitator or an obstacle to a fluent verbal exchange. For example, an appropriate source of lighting directed toward the interlocutor's face will make it easier for the listener to extract the visual speech cues from the communication partner (i.e., the use of speechreading, facial expressions). On the other hand, a source of light emanating from behind the interlocutor may create a lighting contrast that makes it difficult to see the details of the talker's face.

Related to speech communication, the presence of background acoustic noise typically constitutes the single most important obstacle to fluent conversations. Noise may be defined as any unwanted signal. For example, when two or more persons are having a conversation in a cafeteria, the sound generated by the other persons conversing and the clanging of utensils and dishes are considered to be sources of noise. The primary effect of background noise is a decrement in the speech signal-to-noise ratio (SNR), that is the difference in the level of the intended acoustic signal relative to the level of the background noise. For young normal hearing adults, a SNR of at least $+1 \mathrm{~dB}$ is required to ensure good speech understanding [34]. Older adults with hearing loss require a SNR of approximately $+15 \mathrm{~dB}$ to optimize speech understanding [35]. Similarly, reverberation may have a deleterious effect on speech understanding [36]. Reverberation can be defined as the persistence of a sound after its source has stopped, caused by the reflection of the sound in a closed space. In a typical closed environment, the speech signal arriving at the listener's ear will be comprised of the speech signal emanating directly from the talker as well as numerous renditions of the same speech signal arriving at the ears after being reflected from the ceiling, floor and walls. Hence, there is a slight delay (in the 


\section{VIGNETTE 1 | Anticipation Strategies}

Mrs. A was recently hired by a nursing home. She previously worked as a nurse in a private clinic, but since the COVID-19 outbreak, she decided to re-orient her career. Today, she must attend to Mr. B, a male patient of 95 years-old, who requires blood work. Before entering Mr. B's room, Mrs. A puts on her complete protective gear, including a surgical face mask and a plastic face shield. Mr. B is watching television, with is back to the door. The lights are lightly dimmed, and Mr. B is not wearing is hearing aids, which are on the night table. While she prepares the equipment needed, Mrs. A explains to Mr. B that she will draw blood. Mrs. A then takes a seat beside Mr. B in order to begin the blood test. It is only then that Mr. B, notices her presence in the room. He is surprised and startled. He does not understand what this woman, wearing a complete protective attire, is doing in his room. Because of the face mask and shield, Mrs. A's speech is muffled and incomprehensible.

To optimize communication in this setting, Mrs. A could have used anticipation strategies:

1. Flashed the lights to warn Mr. B that someone was entering the room or walked in his line of sight and greet him good morning.

2. Turned-on the lights to ensure good lighting, closed the bedroom door and turned off the television to reduce ambient noise as much as possible.

3. Asked Mr. B to verify if the hearing aid batteries were operational and then put on his hearing aids (assisting him if help was needed).

4. Asked if Mr. B understood correctly or if he needed clarifications.

\section{VIGNETTE 2 | Repair Strategies.}

Mr. M, a 70-year-old male with a severe hearing loss, comes in the pharmacy to pick up his prescribed medicine. The pharmacist (Ms. F) is wearing a face mask and is standing behind a plexiglass partition. The pharmacist reads Mr. M's prescription and asks if he is familiar with the medication and if he has taken this medication before. Because of the background noise, the mask and the partition, the pharmacist's voice is distorted and too soft for Mr. M to understand what she asked. He replies, somewhat inappropriately, that it was his family physician that prescribed this medication for him. Given his response, the pharmacist repeats (verbatim) what she asked him initially. After several unsuccessful repetitions (and slightly annoyed), the pharmacist finally gives up, and heads for the laboratory counter to prepare the medication. Upon her return, she explains what the medication is for and instructs Mr. M on the daily dosage he should take. Mr. M has difficulty understanding the technical terms used by the pharmacist. Furthermore, he misunderstands the instructions regarding the daily dosage. He understands that he should take two pills in the morning and at night. In fact, the pharmacist had instructed him to "take one pill in the morning, but not in the evening." At the cash register, Mr. M does not hear when the pharmacist informs him of the cost of the medication. He simply gives her his credit card rather than ask her to repeat.

To optimize communication in this setting, the pharmacist could have used repair strategies:

1. Used clear speech (i.e., speak at a slower rate and slightly louder as well as articulate each syllable clearly without exaggerating) when providing information to Mr. M.

2. Stood facing Mr. M and used body language (eyes, eyebrows, gestures and body posture) to communicate more effectively with the face mask.

3. Used a pen and paper to write down the questions and instructions. Also, she could have pointed the window of the cash register to indicate the cost of the medication.

4. Avoided jargon or technical language when giving information to Mr. M about his medication, and used short and simple sentences.

5. Reformulated the instructions to facilitate Mr. M's understanding, rather than simply repeating the same thing.

6. Ensure that Mr. M understood the instructions by asking him what dosage of medication he should take each day.

order of milliseconds) between the direct signal and the reflected signals. This causes a "smearing" of the speech signal perceived by the listener. It should be noted that few communication settings offer a SNR and reverberation time that are optimal for communication.

All communication breakdowns can be accounted for by an obstacle that occurs at one or more of the fours elements of the LIME model of speech communication. Similarly, strategies that are effective in avoiding or repairing a communication breakdown can be associated with one of the four elements of the LIME model.

\section{PANDEMIC SPECIFIC ISSUES}

With the COVID-19 outbreak in countries around the world, the WHO and public health agencies recommend the use of many measures to reduce the transmission of the virus [1]. Some of these recommendations may make communication more arduous for older individuals with hearing loss, whether or not they use hearing aids.

\section{Physical Distancing}

Physical distancing (e.g., keeping a distance of $2 \mathrm{~m}$ between the communication partners) is not optimal for communication, especially in the presence of background noise and when one of the communication partners has hearing loss or visual impairment. The level of a sound decreases as a function of the distance from the source of the sound. In a free field (i.e., when there is no reverberation), the level of an acoustic signal decreases by $6 \mathrm{~dB}$ each time the distance from the sound source is doubled [37]. Under normal conditions, the physical distance between two individuals conversing is about $1 \mathrm{~m}$. When the $2 \mathrm{~m}$ social distancing rule is applied, the speech signal from the conversational partner may be sufficiently attenuated to create speech understanding difficulties for the person receiving the message.

\section{Masks, Face Shields and Transparent Partitions}

The results of recent investigations have revealed that the surgical mask acts as an acoustical low-pass filter, reducing the level of high-frequency sounds (between 2 and $7 \mathrm{kHz}$ ) [38,39]. The overall sound attenuation recorded when using a surgical mask is approximately $4 \mathrm{~dB}$; an attenuation of $6-12 \mathrm{~dB}$ was observed when a N95 mask is used. Although face shields and masks with windows allow for speechreading, they attenuate the speech signal more than opaque cloth masks, with an attenuation of 11-14 dB [38]. Studies that have investigated the acoustic properties of facial protective devices confirm that the use of 


\section{VIGNETTE 3 | Anticipation, Repair and Maintenance Strategies.}

Mrs. Y is a general nurse-practitioner. Because of the pandemic, in order to reduce social contacts and limit the spread of the COVID-19, many of her appointments are conducted by telephone. She conducts her interviews from her hospital office, which is adjacent to a general waiting area shared by several practitioners. Today is a particularly busy day in the clinic and the level of noise in the waiting room is quite high. Mrs. Y's 10-o'clock appointment is with Mr. D, a 65-year-old male with a known age-related hearing loss. Wanting to show her open attitude toward her patients and co-workers, Mrs. Y typically leaves her office door open even during appointments. Mrs. Y uses the hand-free option on her cellphone to call her patient. This allows her to take notes on the computer at the same time as she conducts the interview. Because she is running late in her appointments, Mrs. Y goes straight to the point and questions Mr. D on his symptoms. Mr. D struggles to understand Mrs. Y's questions, because there seems to be a lot of echo and background noise coming from the telephone. Mrs. Y talks too quickly for Mr. D. to understand her. Consequently, for almost every question he is asked, Mr. D. needs several repetitions before he understands and answers the question.

To optimize communication in this setting, Mrs. Y could have used multiple strategies:

1. Shut the door of her office to reduce background noise and reverberation, that is being transmitted over the telephone line (anticipation strategy).

2. Used earphones with an integrated microphone with her telephone, or at least, not use the hand-free function in order to reduce the reverberation and the background noise (anticipation strategy).

3. Introduced herself before starting the interview, verified that Mr. D. could hear her well and then ask what the general reason for the consultation was (anticipation strategy).

4. Used alternate ways to seek the information sought rather than always repeating exactly the same thing every time Mr. D. asked for a repetition (repair strategy).

5. Used clear speech (repair strategy).

6. Considered using videoconferencing (thus allowing the use of visual cues) (maintenance strategy).

7. Verified with Mr. D that he was hearing well the questions and asked him to provide confirmation during the interview that he understood well (maintenance strategy).

masks and shields can have a considerable negative impact on speech understanding as well as deleterious effects on secondary and tertiary issues related to hearing and communication (e.g., anxiety, fatigue and stress). In Italy, a research team investigated the impact of protective measures against COVID-19 among individuals with hearing loss who were hospitalized [40]. More than $85 \%$ of the patients questioned reported communication difficulties related to the implementation of protective measures. Related to wearing a mask, eliminating the possibility of lipreading was identified as the main source of communication disturbance in $55 \%$ of the participants questioned.

Also, the use of face masks may have detrimental psychological effects, which could impact communication as well as the quality of health services provided. For instance, Metha et al. (2020) reported that face masks decrease the feeling of trust between the patient and the health care provider [41]. Further, it is more difficult for the communication partners (e.g., the patient and the professional) to decode emotions when the only facial expression available is the other person's eyes and eyebrows.

Three of the strategies most recommended for countering the deleterious effects of background noise are: 1) eliminate or reduce the background noise (i.e., improve the SNR), 2) provide visual cues so that the listener can use speechreading to complement the less than ideal acoustic speech signal and, 3) reduce the distance between the two interlocutors. However, pandemic protective measures, such as the use of a face mask and physical distancing, preclude the use of some of those strategies.

\section{Communication Technologies}

With the COVID-19 pandemic, there has been a sudden increase in the use of telehealth. Many health care professionals now rely on the telephone or videoconferencing to provide health care services to their patients. Although these communication technologies serve to reduce the risk of transmitting an infectious disease, they can be obstacles to effective communication for older adults, especially for those with hearing difficulties. The primary obstacles to distance communication include (but may not be limited to): the quality of the communication device (i.e., telephone, computer, tablet, smartphone) and Internet connection, the quality of the acoustic signal (mainly influenced by the quality of the loudspeakers or earphones used), a poor temporal synchrony between the acoustic and the visual signals when videoconferencing and the lack of access to visual cues while using the telephone. These factors may interfere with the fluency of speech communication and lead to communication breakdowns. It is also important to keep in mind that although older adults report mainly positive attitudes toward the use of technologies [42], they may have less comfort and competence with the use of hightechnology communication devices such as computers, smartphones and tablets [43].

\section{STRATEGIES TO OPTIMIZE COMMUNICATION}

As mentioned previously, communication is a shared responsibility between the listener and the interlocutor. Given this premise, using appropriate communication strategies is the responsibility of all communication partners. Communication strategies may be defined as the set of attitudes, knowledge, actions and requests that can be used to promote more effective communication [29]. A communication breakdown occurs when the listener does not comprehend the message provided by the interlocutor. Applying appropriate communication strategies makes communication more efficient, allows for a more pleasant communication experience and is beneficial for all the people involved in the conversations. There are three main categories of communication strategies [4,29]: 1) anticipation strategies, 2) repair strategies and 3) maintenance strategies.

\section{Anticipation Strategies}

Anticipation strategies are employed to avoid or minimize communication breakdowns. They aim to anticipate difficult situations. For example, closing the door leading to a noisy 
TABLE 1 | Strategies for face to face, telephone and videoconferencing conversations based on the LIME communication chain.

\begin{tabular}{|c|c|c|c|c|}
\hline & Listener & Interlocutor & Message & Environment \\
\hline $\begin{array}{l}\text { Shared (face to face } \\
\text { and distance) }\end{array}$ & $\begin{array}{l}\text { - Explain how the other person } \\
\text { can help you: Speak slightly } \\
\text { louder with good enunciation } \\
\text { - Share what you heard (or think } \\
\text { you heard) } \\
\text { - Include a friend or family } \\
\text { member to ensure } \\
\text { understanding or offer to come } \\
\text { along to listen and take notes } \\
\text { when a friend or family member } \\
\text { has an appointment or meeting } \\
\text { - Make sure that you are wearing } \\
\text { your hearing aids and that they } \\
\text { are working } \\
\text { - Request rephrasing after two } \\
\text { repeats }\end{array}$ & $\begin{array}{l}\text { - Use the eyes, eyebrows, hand } \\
\text { gestures and body posture to } \\
\text { communicate more effectively } \\
\text { and to facilitate the } \\
\text { understanding of the message } \\
\text { - Make sure the other person } \\
\text { understands what you told } \\
\text { them by asking them if they } \\
\text { understood correctly or if they } \\
\text { need clarification } \\
\text { - Allow time for the other person } \\
\text { to express themselves } \\
\text { - Speak a little louder and clearly } \\
\text { while remaining natural; do not } \\
\text { shout, as this can make it more } \\
\text { difficult for the other person to } \\
\text { read lips and distort speech } \\
\text { - Speak slower. Be } \\
\text { understanding and stay calm }\end{array}$ & $\begin{array}{l}\text { - Speak one at the time. Respect } \\
\text { the speaking turn } \\
\text { - Use short sentences and pause } \\
\text { between each } \\
\text { - Avoid jargon or technical } \\
\text { language; use everyday speech }\end{array}$ & $\begin{array}{l}\text { - Make sure you have good } \\
\text { lighting; make sure it is facing } \\
\text { your face rather than } \\
\text { behind you } \\
\text { - Reduce ambient noise as } \\
\text { much as possible. When } \\
\text { possible move to quieter spot } \\
\text { or turn down the noise }\end{array}$ \\
\hline Face to face & $\begin{array}{l}\text { - Make sure that you are wearing } \\
\text { your hearing aids and glasses } \\
\text { - If necessary, use a personal } \\
\text { listening device while following } \\
\text { appropriate infection control } \\
\text { protocols }\end{array}$ & $\begin{array}{l}\text { - Stand facing to the other } \\
\text { person, even if you are wearing } \\
\text { a mask } \\
\text { - Get the other person's attention } \\
\text { by saying their name or } \\
\text { gesturing first }\end{array}$ & $\begin{array}{l}\text { - When necessary, use pen and } \\
\text { paper to write down what you } \\
\text { want to say to the other person. } \\
\text { Or, use the smartphone talk-to- } \\
\text { text application to communicate } \\
\text { - Make the instructions accessible } \\
\text { in writing (e.g., a sign stating to } \\
\text { show the medical card at the } \\
\text { reception) }\end{array}$ & $\begin{array}{l}\text { - Be mindful of distance. As } \\
\text { distance increases, sound } \\
\text { levels decrease, and visual } \\
\text { cues are more difficult to see }\end{array}$ \\
\hline $\begin{array}{l}\text { Distance (telephone } \\
\text { and videoconferencing) }\end{array}$ & $\begin{array}{l}\text { - Use assistive listening devices } \\
\text { (e.g., connect hearing aids with } \\
\text { the computer or the telephone) } \\
\text { - Make sure to have a good } \\
\text { internet or phone reception } \\
\text { - Use proper earphones and } \\
\text { microphone }\end{array}$ & $\begin{array}{l}\text { - Use mute mode if you are not } \\
\text { speaking to reduce } \\
\text { background noise } \\
\text { - Make sure to have a good } \\
\text { internet or phone reception } \\
\text { - Before the start of the } \\
\text { consultation, confirm with the } \\
\text { other person that he can hear } \\
\text { and understand you } \\
\text { - Do not use the hands-free } \\
\text { function when you are talking to } \\
\text { the other person } \\
\text { - Do not cover your mouth with } \\
\text { your hands }\end{array}$ & $\begin{array}{l}\text { - When possible, favor the use of } \\
\text { written communication (e.g., } \\
\text { email) for confirmation of } \\
\text { appointments } \\
\text { - Ask that each speaker announce } \\
\text { their name before they begin } \\
\text { speaking } \\
\text { - Use speech-to-text captioning } \\
\text { when available } \\
\text { - Consider using a speech to text } \\
\text { app (e.g., my call to text) } \\
\text { - Consider whether a relay service } \\
\text { would be beneficial }\end{array}$ & $\begin{array}{l}\text { - Speak in a room that is less } \\
\text { reverberant }\end{array}$ \\
\hline
\end{tabular}

hallway before conversing with an older adult with hearing loss would be an appropriate anticipation strategy. Likewise, verifying that a patient's hearing aids are functioning properly before conducting a medical case history would be classified as an anticipatory strategy. Typical anticipation strategies include informing others about difficulty hearing, modifying the physical environment and informing about the subject and the terminology before the conversation. Vignette 1 illustrates examples of anticipation strategies.

\section{Repair Strategies}

Repair strategies are actions taken to restore the conversational flow after a communication breakdown occurs. For example, repeating the message while using louder and clearer speech is a form of repair strategy used to overcome a communication breakdown. Clear speech is characterized by a spoken signal that is slightly louder, articulated precisely, uttered at a slower than normal rate, and it includes the insertion of natural pauses between words, phrases and sentences. Although all of those 
modifications generate a signal that optimizes speech intelligibility, it is important not to exaggerate any of the suggested speech manipulations. The most appropriate repair strategies to use will depend on the source or the cause of the communication breakdown. Applying the LIME model (Listener, Interlocutor, Message or Environment) outlined earlier may be a good way to identify possible sources of a communication breakdown. For example, if it is determined that the breakdown is attributable to an inattentive listener, an efficient repair strategy would be to capture the listener's attention before repeating the intended message. Typical repair strategies include asking to specify, clear speech, reformulating and using a synonym, elaborating, using non-verbal and body language, giving the context of the conversation and spelling or writing. Vignette 2 provides examples of repair strategies.

\section{Maintenance Strategies}

Finally, maintenance strategies are used to demonstrate a person's interest and active participation in the ongoing conversation. Nodding to signal to the communication partner that the message was understood is a common and effective maintenance strategy to use during a conversation. Common maintenance strategies include physical proximity, visual contact, facial expressions and providing confirmation and feedback. Vignettes 3 provides examples of maintenance strategies.

\section{Summary of Communication Strategies}

Based on the LIME model, Table 1 provides a summary of communication strategies that health care professionals can use in order to improve communication with patients that experience hearing difficulties either during a face-to-face conversation or while using the telephone or videoconferencing.

\section{CONCLUSION}

In the context of a pandemic, effective communication may be more at risk than usual because protective and preventive measures are applied while providing health care services. Protective measures that may negatively impact speech communication include physical distancing, the use of face masks and shields as well as the increased use of telephone and videoconferencing for distance communication. Older adults, especially those with hearing loss, are particularly at

\section{REFERENCES}

1. WHO [Internet]. Coronavirus (2019). Available from: https://www.who.int/ health-topics/coronavirus (Accessed November 7, 2020).

2. Montano, JJ Audiologic Rehabilitation. in: J Katz, M Chasin, K English, LJ Hood, and KL Tillery, editors. Handbook of Clinical Audiology. 7th ed. Philadelphia, PA: Lippincott Williams \& Wilkins (2015). p. 849-60.

3. Montano, JJ, and Spitzer, JB Adult Audiologic Rehabilitation. San Diego, CA: Plural Publishing (2020).

4. Tye-Murray, N Foundations of Aural Rehabilitation: Children, Adults, and Their Family Members. 5th ed. San Diego, CA: Plural Publishing (2019). risk of experiencing communication breakdowns and increased social isolation. Using hearing aids may help overcome the loss of signal intensity. However, they do not restore normal hearing and do not improve the loss of clarity. Communication strategies (anticipation, repair and maintenance strategies) should be used by all partners involved in the communication situation, including the health care professional, in order to maintain good interactions and prevent communication breakdowns. In almost every country, there are professionals trained to provide hearing health care services (e.g., audiologists, otologists/otorhinolaryngologists, hearing aids specialists and speech-language pathologists). Some of these professionals are responsible for the prevention, assessment and treatment of hearing disorders and provide hearing rehabilitation services for individuals with hearing difficulties. For more information concerning any issues related to hearing and communication, it is suggested that the health care professional consult the accredited hearing health care professional in their jurisdiction.

\section{AUTHOR CONTRIBUTIONS}

Conceptualization: AP-S, ABML, MH, and J-PG. Writing-Original Draft: AP-S. Writing-Review and Editing: AP-S, ABML, MH, and J-PG. All authors read and approved the final manuscript. The corresponding author attests that all listed authors meet authorship criteria and that no others meeting the criteria have been omitted.

\section{FUNDING}

Funding for publication fees was provided by the Chaire de la Fondation Caroline-Durand en audition et vieillissement de l'Université de Montréal. The endowed research chair is held by J-PG.

\section{CONFLICT OF INTEREST}

The authors declare that the research was conducted in the absence of any commercial or financial relationships that could be construed as a potential conflict of interest.

5. Grant, KW, and Braida, LD. Evaluating the Articulation Index for Auditory-Visual Input. The J Acoust Soc America (1991). 89(6):2952-60. doi:10.1121/1.400733

6. MacLeod, A, and Summerfield, Q. Quantifying the Contribution of Vision to Speech Perception in Noise. Br J Audiol (1987). 21(2):131-41. doi:10.3109/ 03005368709077786

7. MacLeod, A, and Summerfield, Q. A Procedure for Measuring Auditory and Audiovisual Speech-Reception Thresholds for Sentences in Noise: Rationale, Evaluation, and Recommendations for Use. Br J Audiol (1990). 24(1):29-43. doi:10.3109/03005369009077840

8. WHO [Internet]. Prevention of Blindness and Deafness: Estimates (2018). Available from: https://www.who.int/pbd/deafness/estimates/en/ (Accessed November 7, 2020).

9. Shewan, CM. The Prevalence of Hearing Impairment. ASHA (1990). 32(2):62. 
10. Government of Canada, Statistics Canada. [Internet]. Hearing Loss of Canadians, 2012 to 2015 (2015). Available from: https://www150.statcan.gc. ca/n1/pub/82-625-x/2016001/article/14658-eng.htm (Accessed November 7, 2020).

11. Weinstein, BE In: BE Weinstein, editor. Geriatric Audiology. 2nd ed. New York, NY: Thieme Medical (2013).

12. Gagné, JP. Troubles de l'audition. In: Arcand M and Hébert R, editors. Précis pratique de gériatrie (2007). p. 527-41.

13. Yamasoba, T, Lin, FR, Someya, S, Kashio, A, Sakamoto, T, and Kondo, K. Current Concepts in Age-Related Hearing Loss: Epidemiology and Mechanistic Pathways. Hearing Res (2013). 303:30-8. doi:10.1016/j.heares.2013.01.021

14. Tavanai, E, and Mohammadkhani, G. Role of Antioxidants in Prevention of Age-Related Hearing Loss: a Review of Literature. Eur Arch Otorhinolaryngol (2017). 274(4):1821-34. doi:10.1007/s00405-016-4378-6

15. Wong, ACY, and Ryan, AF. Mechanisms of Sensorineural Cell Damage, Death and Survival in the Cochlea. Front Aging Neurosci (2015). 7:58. doi:10.3389/ fnagi.2015.00058

16. Caron, H. Guide du professionnel de la santé et de l'intervenant auprès de la personne aînée ou adulte ayant des problèmes d'audition. (2014). Montréal, QC: Institut Raymond-Dewar, Fondation de la surdité de Montréal, Le Groupe Forget audioprothésistes.

17. Ferguson, MA, Kitterick, PT, Chong, LY, Edmondson-Jones, M, Barker, F, and Hoare, DJ. Hearing Aids for Mild to Moderate Hearing Loss in Adults. Cochrane Database Syst Rev (2017). 9:CD012023. doi:10.1002/14651858. CD012023.pub2

18. Wallhagen, MI, Strawbridge, WJ, and Kaplan, GA. 6-year Impact of Hearing Impairment on Psychosocial and Physiologic Functioning. Nurse Pract (1996). 21(9):11-4.

19. Nachtegaal, J, Festen, JM, and Kramer, SE. Hearing Ability and its Relationship with Psychosocial Health, Work-Related Variables, and Health Care Use: the National Longitudinal Study on Hearing. Audiol Res (2011). 1(1):28-33. doi:10.4081/audiores.2011.e9

20. Tambs, K. Moderate Effects of Hearing Loss on Mental Health and Subjective Well-Being: Results from the Nord-Trøndelag Hearing Loss Study. Psychosom Med (2004). 66(5):776-82. doi:10.1097/01.psy. 0000133328.03596.fb

21. Savundranayagam, MY, Hummert, ML, and Montgomery, RJV. Investigating the Effects of Communication Problems on Caregiver Burden. Journals Gerontol Ser B: Psychol Sci Soc Sci (2005). 60(1):S48-S55. doi:10.1093/ geronb/60.1.S48

22. Lin, FR, Metter, EJ, O'Brien, RJ, Resnick, SM, Zonderman, AB, and Ferrucci, L. Hearing Loss and Incident Dementia. Arch Neurol (2011). 68(2):214-20. doi:10.1001/archneurol.2010.362

23. Lin, FR, Yaffe, K, Xia, J, Xue, Q-L, Harris, TB, Purchase-Helzner, E, et al. Hearing Loss and Cognitive Decline in Older Adults. JAMA Intern Med (2013). 173(4):293-9. doi:10.1001/jamainternmed.2013.1868

24. Lin, F. How Is Hearing Loss Related to Cognitive Decline and Dementia?. AudiologyOnline (2019).

25. Ask, H, Krog, NH, and Tambs, K. Impact of Hearing Impairment on Spousal Mental Health: the Nord-Trondelag Health Study. Eur J Public Health (2010). 20(3):271-5. doi:10.1093/eurpub/ckp176

26. Preminger, JE, Montano, JJ, and Tjørnhøj-Thomsen, T. Adult-children's Perspectives on a Parent's Hearing Impairment and its Impact on Their Relationship and Communication. Int J Audiol (2015). 54(10):720-6. doi:10.3109/14992027.2015.1046089

27. Scarinci, N, Worrall, L, and Hickson, L. The Effect of Hearing Impairment in Older People on the Spouse. Int J Audiol (2008). 47(3):141-51. doi:10.1080/ 14992020701689696

28. Scarinci, N, Worrall, L, and Hickson, L. The ICF and Third-Party Disability: Its Application to Spouses of Older People with Hearing Impairment. Disabil Rehabil (2009). 31(25):2088-100. doi:10.3109/09638280902927028a
29. Gagné, JP, and Jennings, MB. Audiologic Rehabilitation Intervention Services for Adults with Acquired Hearing Impairment. In: editors. M Valente and H Hosford-Dunn, Audiology: Treatment; (2008).

30. WHO [Internet]. International Classification of Functioning, Disability and Health (ICF) (2019). Available from: https://www.who.int/classifications/icf/ en/ (Accessed November 7, 2020).

31. Lacerda, A, Tat, W, Bourgeois, C, and Gagné JP. (2020). L'audition et la communication chez l'aîné [Internet]. Available from: https://webinaire. criugm.qc.ca/sante-physique/ (Accessed November 7, 2020).

32. Schneider, BA, Daneman, M, and Pichora-Fuller, MK. Listening in Aging Adults: from Discourse Comprehension to Psychoacoustics. Can J Exp Psychology/Revue canadienne de Psychol expérimentale (2002). 56(3): 139-52. doi:10.1037/h0087392

33. Bryant, C, Jackson, H, and Ames, D. The Prevalence of Anxiety in Older Adults: Methodological Issues and a Review of the Literature. J Affective Disord (2008). 109(3):233-50. doi:10.1016/j.jad.2007.11.008

34. Crandell, C, and Smaldino, J. In: Room Acoustics for Listeners with Normal Hearing and Hearing Impairment. M Valente, R Roeser, and H Hosford-Dunn, editors. New York, NY: Thieme Medical (2000). p. 601-37.

35. American Speech-Language-Hearing Association. Guidelines for Acoustics in Educational Environments. ASHA (1995). 37(14):15-9.

36. Helfer, KS, and Wilber, LA. Hearing Loss, Aging, and Speech Perception in Reverberation and Noise. J Speech Lang Hear Res (1990). 33(1):149-55. doi:10. 1044/jshr.3301.149

37. Occupational Safety and Health Administration [Internet]. OSHA Technical Manual (OTM), Section III, Chapter 5 (2013). Available from: https://www.osha.gov/dts/osta/otm/new_noise/index.html (Accessed November 7, 2020).

38. Corey, RM, Jones, U, and Singer, AC. Acoustic Effects of Medical, Cloth, and Transparent Face Masks on Speech Signals. J Acoust Soc America (2020). 148(4):2371-5. doi:10.1121/10.0002279

39. Goldin, A, Weinstein, BE, and Shiman, N. (2020). How Do Medical Masks Degrade Speech Reception? Hearing Review [Internet]. Available from: https:// www.hearingreview.com/hearing-loss/health-wellness/how-do-medical-masksdegrade-speech-reception (Accessed November 7, 2020).

40. Trecca, EMC, Gelardi, M, and Cassano, M. COVID-19 and Hearing Difficulties. Am J Otolaryngol (2020). 41(4):102496. doi:10.1016/j.amjoto. 2020.102496

41. Mehta, UM, Venkatasubramanian, G, and Chandra, PS. The "mind" behind the "mask": Assessing Mental States and Creating Therapeutic Alliance amidst COVID-19. Schizophrenia Res (2020). 222:503-4. doi:10.1016/j.schres.2020. 05.033

42. Mitzner, TL, Boron, JB, Fausset, CB, Adams, AE, Charness, N, Czaja, SJ, et al. Older Adults Talk Technology: Technology Usage and Attitudes. Comput Hum Behav (2010). 26(6):1710-21. doi:10.1016/j.chb.2010.06.020

43. Czaja, SJ, Charness, N, Fisk, AD, Hertzog, C, Nair, SN, Rogers, WA, et al. Factors Predicting the Use of Technology: Findings from the Center for Research and Education on Aging and Technology Enhancement (CREATE). Psychol Aging (2006). 21(2):333-52. doi:10.1037/0882-7974.21.2.333

Copyright (c) 2021 Pinsonnault-Skvarenina, Lacerda, Hotton and Gagné. This is an open-access article distributed under the terms of the Creative Commons Attribution License (CC BY). The use, distribution or reproduction in other forums is permitted, provided the original author(s) and the copyright owner(s) are credited and that the original publication in this journal is cited, in accordance with accepted academic practice. No use, distribution or reproduction is permitted which does not comply with these terms.

PHR is edited by the Swiss School of Public Health (SSPH+) in a partnership with the Association of Schools of Public Health of the European Region (ASPHER)+ 